\title{
Lymphoproliferative cancer and other malignancy in patients with rheumatoid arthritis treated with azathioprine: a 20 year follow up study
} ALAN J SILMAN ${ }^{1}$ JOHN PETRIE, ${ }^{*}$ BRIAN HAZLEMAN, ${ }^{2}$ AND STEPHEN J W
EVAN

From the ${ }^{1}$ Department of Clinical Epidemiology, The London Hospital Medical College; and the $\vec{\Omega}^{\bar{D}}$ ${ }^{2}$ Rheumatology Research Unit, Addenbrooke's Hospital, Cambridge

SUMMARY Two hundred and two patients with rheumatoid arthritis (RA) starting treatment with large doses of azathioprine (median $300 \mathrm{mg} /$ day) between 1964 and 1974 were followed up $\infty$ until March 1984. All but one patient (99.5\%) were traced from either hospital or general 웅 practice records; and death certificates, where relevant, were obtained. A comparison group of 202 patients with RA not treated with azathioprine was selected from the diagnostic index of ${ }_{D}$ another rheumatology unit and followed up in 1985 to assess their status retrospectively at March $\underset{\varnothing}{\varnothing}$ 1984. Each patient treated with azathioprine was matched for year of birth, year of diagnosis, $\frac{\mathbb{3}}{3}$ sex, and serostatus with a control patient from the latter group. Four lymphoproliferative cancers $\stackrel{\Phi}{-}$ occurred in the azathioprine treated group compared with two in the control group. Furthe $\vec{v}$ analysis of these findings suggested an increased risk of lymphoma of one case per 1000 patien $\infty$ years of azathioprine treatment. The lymphoma rates were then compared with those expecteg based on the incidence in the general population. This comparison suggested a fivefold increase in the RA control group and a 10 -fold increase in the azathioprine treated group. There was also an excess of patients with non-lymphoproliferative cancers, including one with myeloma in the azathioprine group (29v19), the excess being greater in the group with the longest duration of treatment. This significantly increased risk did not, however, persist on matched analysis, was not $\bar{\partial}$ related to maximum daily dose, and was not site specific. These results from a possibly unique series of patients treated with high dose azathioprine give some reassurance about the magnitude of the previously postulated carcinogenic risk of such treatment in RA.

Immunosuppressive drugs have been used for the last 30 years in the treatment of patients with severe rheumatoid arthritis (RA). There is evidence that they can reduce synovitis, and further, azathioprine has been shown to be as effective as gold when started early in the disease. Long term treatment with such agents is frequently indicated in order to maintain any remission induced, and hence there is a need to study prospectively the incidence of potentially severe adverse side effects.

Accepted for publication 12 May 1988

Correspondence to Alan J Silman, Department of Clinical Epidemiology, The London Hospital Medical College, London E1 1BB.

*Present address: Queen Elizabeth Hospital, Rotorua, New Zealand.
In 1979 Kinlen et al demonstrated a 58-fold increased risk of non-Hodgkin lymphoma in patients with transplants, and a 12-fold increase in patients without transplants, treated with immunosuppres- $\frac{}{x}$ sive therapy, including 643 with RA. ${ }^{1}$ The relative $\rightarrow$ risk of reticuloendothelial cancer for patients in the group which had received azathioprine was $13 \cdot 5 .{ }^{12}$ N In 1980, however, a follow up was reported from Newmarket of 202 patients treated with high dose 0 azathioprine from 1964 to 1975 and followed up $\omega$ until 1976. ${ }^{3}$ These patients were unusual in receiving up to $5 \mathrm{mg} / \mathrm{kg}$ body weight of azathioprine a day, $\varnothing$ often in conjunction with other disease modifying $\Phi$ drugs, such as gold. ${ }^{3}$ Reassuringly that analysis did $\stackrel{?}{\cdot}$ not demonstrate any excess of reticuloendothelial $\underline{T}$ cancer deaths, and indeed, there was no case of nonHodgkin lymphoma during the relatively short 
follow up period. It was therefore decided to extend the follow up of this group for a further 10 years to determine whether an increased risk of reticuloendothelial cancer would become apparent.

Any increase in such risk had to be considered in the context of a possible increased risk in patients with RA not treated with azathioprine. There are conflicting results on this subject with some studies finding an increased risk ${ }^{4} 5$ and others no increase in risk. ${ }^{6} 7$ This disparity may reflect methodological differences, with the positive reports coming from the more sensitive method of cohort morbidity analysis. ${ }^{8}$ In one of the most recent studies an eightfold increase in incidence of reticuloendothelial cancer in patients with RA was observed,${ }^{5}$ though, interestingly, none of the patients that developed a lymphoma had been treated with azathioprine.

Thus it was hoped that by comparing the reticuloendothelial cancer risk in the Newmarket patients, given their unique exposure to high dose azathioprine over a long period, with that of a control group of patients with RA not treated with azathioprine, this particular aspect of azathioprine safety could be usefully evaluated.

\section{Patients and methods}

\section{PATIENTS}

The exposed group consisted of the original 204 patients from Newmarket, of whom records were available for $202(99 \%)$. Each of these patients $(57$ (28\%) male, $145(72 \%)$ female) had RA and had been treated with azathioprine. The mean age at diagnosis was 43.8 years (SD 19), and $183(91 \%)$ had been recorded as seropositive at some stage in their illness. All had started treatment with azathioprine between 1964 and 1975 and had received this treatment for a median of 35 months (range 1-222) with a median daily dose of $300 \mathrm{mg}$ (range 150-400). Full details of the dosage regimen used have been described previously. ${ }^{3}$

Selection of the control group was more problematic. This was not a randomised controlled trial and thus there were no natural local controls. It was therefore necessary to search for an alternative control group of patients with RA for whom a similar duration of follow up information was available. The London Hospital has had a diagnostic index since 1970 and includes about 2500 patients with RA who first attended that hospital between 1948 and 1983. The social class and urban/rural differences in the incidence of reticuloendothelial cancers are insufficiently large $\mathrm{e}^{9}$ to bias a comparison of reticuloendothelial cancer incidence between London and Newmarket in either direction. Each azathioprine treated patient was therefore matched to a non-treated patient with RA from The London Hospital as follows: $(a)$ year of birth and year of diagnosis were the same plus or minus five years. (This was not possible for approximately 20 of the patients treated with azathioprine and thus the nearest available control patient was selected. This matching aimed to provide equivalence in both age and disease duration for follow up); (b) same sex; (c) seropositivity as a single index of disease severity.

FOLLOW UP

All of the 404 patients (202 exposed, 202 nonexposed) were tracked as far as possible to identify their status at 31 March 1984. Many were still attending hospital for their rheumatoid arthritis and thus the development or otherwise of lymphoproliferative or other cancer could be gleaned from the case records. In other instances the patients had died or developed cancer during active follow up with adequate details being available in the records. For the remaining patients their last recorded general practitioner was contacted for the necessary information.

With these approaches only one patient from the azathioprine group lacked complete follow up data. The follow up of the non-exposed group was initially less satisfactory, with only $70 \%$ of these patients having complete follow up data. This is perhaps not surprising given the higher population mobility in the London area. The cancer status for the missing $30 \%$ of the non-exposed group was subsequently obtained from the National Health Service central register, and only eight $(4 \%)$ remained untraced. Death certificates were obtained for all patients known to have died from the Office of Population, Censuses, and Surveys.

Follow up was continued to death, diagnosis of cancer, and for the remainder until 31 March 1984.

A N A L Y S IS

The analytical methods used allowed for the differences in follow up between the two groups. Each control was given a dummy date for the start of azathioprine treatment. This date was calculated as the time interval after their diagnosis corresponding to the interval between diagnosis and treatment in their matched case. The total number of person years at risk was calculated for each group based from the start (true or dummy) of azathioprine treatment to the end of follow up. The incidence of lymphoproliferative malignancy (ICD codes 200202), and of all cancers, per 1000 person years at risk was then calculated for both groups. The total person years at risk were then subdivided into sex and 10 year age groups to allow the expected 
lymphoproliferative and all cancer incidence to be calculated based on the appropriate published national rates for the median calendar year of follow up. ${ }^{9}$ Calculation of the expected incidence in both groups permitted a check on the closeness of matching. Thus the better the matching, the more similar the distribution of the age specific years at risk and hence the closer should be the expected number of cases in both groups.

The analysis was also carried out with the matching retained. If either the case or control in a given pair had developed a cancer before this treatment start day the pair were excluded from the analysis. This applied to 15 pairs: 12 in whom the control had developed cancer before the matched case had started azathioprine and three cases with a cancer history antedating the start of azathioprine. A matched pair analysis was undertaken to obtain the estimate for relative risk based on the number of pairs discordant for cancer-that is, by testing the null hypothesis that there are equal numbers of such pairs with either the azathioprine case or matched control with a cancer. In the azathioprine group the incidence of cancer was further examined in relation to dose in three ways: $(a)$ by total duration of treatment, dividing the group into thirds; $(b)$ by maximum daily dose; $(c)$ by an estimate of total dose obtained by adding together the products of duration and daily dose for each patient. Four total dose ranges were chosen $<10 \mathrm{~g}, 10-50 \mathrm{~g}, 50-200 \mathrm{~g}$, and $>200 \mathrm{~g}$. The trends obtained were examined for

Table 1 Comparison of azathioprine and control groups

\begin{tabular}{lll}
\hline & Azathioprine & Control \\
\hline Mean year of birth & 1920 & 1922 \\
Mean age at diagnosis & $43 \cdot 8$ & $40 \cdot 4$ \\
No of men (\%) & $19(9 \cdot 4)$ & $19(9 \cdot 4)$ \\
Number seropositive (\%) & $183(90 \cdot 6)$ & $183(90 \cdot 6)$ \\
\hline
\end{tabular}

statistical significance by the $\chi^{2}$ test. All analyses were undertaken using the SAS software program version 5.02 on an Amdahl 470/V8.

\section{Results}

The azathioprine and control groups were similar in regard to the matching variables, though the control group was slightly younger at diagnosis (Table 1 ). The overall follow up to a terminating event was $\vec{\circ}$ similar also in both groups with 2260 and 2628 person years respectively in the azathioprine and control groups, with means of 11.19 and 13.01.

There were four lymphoproliferative cancers (three lymphomas, type unspecified and one lymphosarcoma) in the azathioprine group and two (both lymphomas) in the control group. Table 2 gives details of these cases. We cannot exclude the possibility, given the timing available from the medical records, that the patient with a lymphosarcoma in the azathioprine group had not developed the disease before azathioprine treatment. If that case is included there were 1.8 lymphoproliferative cancers per 1000 years of patient follow up in the azathioprine group compared with 0.8 in the control group. This represents an attributable risk of $1 / 100 \mathrm{~g}$ patient years or the development of one extra lymphoproliferative cancer due to azathioprine 1000 patient years of observation. The number of expected lymphomas based on the general population rates for the age and sex specific person years at risk were 0.40 and 0.42 for the azathioprine and non-azathioprine groups respectively. Thus the risk of lymphoma in RA was increased $4 \cdot 8$-fold compared with a 10 -fold increase in azathioprine treated RA.

Fifteen pairs of patients contained one patient with a cancer developing before the start of azathioprine treatment (three treated and 12 control patients) and when these were excluded more nonlymphoproliferative cancers were present in the

Table 2 Details of lymphoproliferative malignancies

\begin{tabular}{|c|c|c|c|c|c|c|c|}
\hline \multirow[t]{2}{*}{ Sex } & \multicolumn{2}{|c|}{ Year of } & \multicolumn{2}{|c|}{ Treatment } & \multicolumn{2}{|l|}{ Malignancy } & \multirow[t]{2}{*}{ Death } \\
\hline & Birth & Diagnosis & Year & $\begin{array}{l}\text { Duration } \\
\text { (months) }\end{array}$ & Type & Diagnosis & \\
\hline \multicolumn{8}{|c|}{ Azathioprine group } \\
\hline $\mathbf{F}$ & 1894 & 1953 & 1971 & 3 & Lymphosarcoma & 1971 & 1972 \\
\hline $\mathbf{M}$ & 1914 & 1966 & 1966 & 86 & Lymphoma & 1980 & 1980 \\
\hline $\mathbf{F}$ & 1914 & 1950 & 1969 & 65 & Lymphoma & 1978 & 1980 \\
\hline $\mathbf{F}$ & 1915 & 1971 & 1972 & 133 & Lymphoma & 1983 & 1983 \\
\hline \multicolumn{8}{|c|}{ Control group } \\
\hline $\mathbf{F}$ & 1893 & 1957 & N/A & N/A & Lymphoma & 1979 & 1981 \\
\hline $\mathbf{M}$ & 1919 & 1960 & N/A & $\mathbf{N} / \mathbf{A}$ & Lymphoma & 1973 & 1976 \\
\hline
\end{tabular}


azathioprine group $(29 v 19,13.4 v 8.3 / 1000$ patient years). The difference in cancer incidence was significant when analysed (ignoring pairing) by the $\log$ rank method $\left(\chi^{2} 1 \mathrm{df} 4 \cdot 7, p=0.031\right)$.

Of the 187 remaining pairs, cancer developed in both members of four pairs, in the azathioprine treated patient only in 25 pairs, and in the control only in 15 pairs. This yielded a non-significantly increased relative risk of $1.67(25 / 15)$ with $95 \%$ confidence interval $0 \cdot 86-3 \cdot 20$. Further, the increased risk overall may be clinically acceptable as it was equivalent to an attributable risk in the azathioprine group of one extra cancer per 217 years of patient observation. Table 3 shows the primary sites of the non-lymphoproliferative cancers in both groups. One other reticuloendothelial tumour, a myeloma, in the azathioprine group developed in a man aged $72 ; 14$ years after finishing a four month course of azathioprine. The distribution by site of non-lymphoproliferative cancers was similar in the two groups. The number of expected non-lymphoproliferative cancers, based on population data, is 15.7 and 17.3 for the azathioprine and control

Table 3 Details on non-lymphoproliferative malignancies

\begin{tabular}{|c|c|c|}
\hline Site & $\begin{array}{l}\text { Azathioprine } \\
\text { (29 patients, } \\
31 \text { primaries) }\end{array}$ & $\begin{array}{l}\text { Controls } \\
\text { (19 patients, } \\
21 \text { primaries) }\end{array}$ \\
\hline Bronchus & 7 & 3 \\
\hline Breast & 6 & 4 \\
\hline Skin & $\begin{array}{l}6 \text { (4 basal cell, } \\
2 \text { squamous) }\end{array}$ & $\begin{array}{r}3 \text { (2 basal cell, } \\
1 \text { squamous) }\end{array}$ \\
\hline Others* & 4 & 6 \\
\hline Large bowel & 2 & 1 \\
\hline Uterus (cervix) & $\begin{array}{l}2 \text { (includes } 1 \\
\text { in situ) }\end{array}$ & 1 \\
\hline Uterus (body) & 2 & 2 \\
\hline Myeloma & 1 & 0 \\
\hline Thyroid & 1 & 1 \\
\hline
\end{tabular}

${ }^{*}$ One case per site. groups, and thus the excess risk of these cancers for both groups was 1.8 and $1 \cdot 1$, interestingly showing no increase in the untreated RA group.

Finally, the risk of cancer in the azathioprine group was analysed in relation to different parameters of dose received. Firstly, the group was divided into thirds based on duration of treatment (Table 4). There was no trend of increasing length of follow up for those with the longest duration of treatment. In addition, there was no significant trend towards an increased cancer risk with increasing duration. Similarly, there was no trend towards increased risk by maximum daily dose (Table 5). Conversely, there was a statistically significant trend towards cancer with increased estimated total dose, using the categories mentioned earlier (Table 6).

Table 5 Maximum daily dose and cancer incidence

\begin{tabular}{llll}
\hline Dose $(g)$ & $\begin{array}{l}\text { No in } \\
\text { group }\end{array}$ & Cancer & \\
\cline { 3 - 4 } & & Yes & No \\
& & No (\%) & No (\%) \\
\hline$<200$ & 21 & $3(14 \cdot 3)$ & $18(85 \cdot 7)$ \\
$200-250$ & 67 & $13(19 \cdot 4)$ & $54(80 \cdot 6)$ \\
$>300$ & 114 & $17(14 \cdot 9)$ & $97(85 \cdot 1)$
\end{tabular}

$\chi^{2}, 1 \mathrm{df}($ trend $)=0 \cdot 113, \mathrm{p}$ NS.

Table 6 Estimated total dose and cancer incidence

\begin{tabular}{|c|c|c|c|}
\hline \multirow{2}{*}{$\begin{array}{l}\text { Total dose } \\
(\mathrm{g})\end{array}$} & \multirow{2}{*}{$\begin{array}{l}\text { No in } \\
\text { group }\end{array}$} & \multicolumn{2}{|l|}{ Cancer } \\
\hline & & $\begin{array}{l}\text { Yes } \\
\text { No (\%) }\end{array}$ & $\begin{array}{l}\text { No } \\
\text { No (\%) }\end{array}$ \\
\hline $\begin{array}{l}<10 \\
10-50 \\
50-200 \\
>200\end{array}$ & $\begin{array}{l}35 \\
24 \\
65 \\
78\end{array}$ & $\begin{aligned} 3 & (8 \cdot 6) \\
2 & (8 \cdot 3) \\
11 & (16 \cdot 9) \\
17 & (21 \cdot 8)\end{aligned}$ & $\begin{array}{l}32(91 \cdot 4) \\
22(91 \cdot 7) \\
54(83 \cdot 1) \\
61(78 \cdot 2)\end{array}$ \\
\hline
\end{tabular}

$\chi^{2}, 1 \mathrm{df}($ trend $)=4 \cdot 10, \mathrm{p}=0 \cdot 043$.

Table 4 Duration of treatment and cancer incidence

\begin{tabular}{|c|c|c|c|c|c|}
\hline \multicolumn{2}{|c|}{$\begin{array}{l}\text { Duration of treatment } \\
\text { (months) }\end{array}$} & \multirow[t]{2}{*}{ No in group } & \multirow{2}{*}{$\begin{array}{l}\text { Mean duration of } \\
\text { follow up (years) }\end{array}$} & \multicolumn{2}{|l|}{ Cancer } \\
\hline Mean & Range & & & $\begin{array}{l}\text { Yes } \\
\text { Number }(\%)\end{array}$ & $\begin{array}{l}\text { No } \\
\text { Number (\%) }\end{array}$ \\
\hline $\begin{array}{l}\text { Shortest } \\
4 \cdot 9\end{array}$ & $1-14$ & 67 & $11 \cdot 8$ & $7(10 \cdot 4)$ & $60(89 \cdot 6)$ \\
\hline $\begin{array}{l}\text { Middle } \\
31 \cdot 0\end{array}$ & $15-48$ & 67 & $8 \cdot 8$ & $13(19 \cdot 4)$ & $54(80 \cdot 6)$ \\
\hline $\begin{array}{l}\text { Longest } \\
95.4\end{array}$ & $49-222$ & 68 & $12 \cdot 8$ & $13(19 \cdot 1)$ & $55(80 \cdot 9)$ \\
\hline
\end{tabular}

$\chi^{2}, 1 \mathrm{df}($ trend) $=1 \cdot 85, \mathrm{p}$ NS. 
This apparent inconsistency may be explained by the fact that the group with the longest duration of treatment (Table 4) covered the broad range 49-222 months, and hence an effect within this band cannot be ruled out.

\section{Discussion}

The main conclusion is that any relative increase in lymphoma risk from azathioprine treatment is likely to be small in relation to the relative increase in 'background' risk in RA generally and is perhaps clinically acceptable. The doses of azathioprine used were twice the currently advised maximum of 2.5 $\mathrm{mg} / \mathrm{kg}$ daily, and perhaps fears concerning the lymphoma risk from using this agent for treatment of RA are excessive. There is no reason to believe that Newmarket residents were at a lower baseline risk which might have explained the disparity between these results and those of others. ${ }^{1}$ The total excess ratio of six lymphoproliferative cancers observed $(0.82$ expected) in the total study population is similar to the nine observed ( 1.13 expected) for all reticuloendothelial cancers reported by Prior et al in a similar sized cohort of rheumatoid patients followed up for a similar period. ${ }^{5}$

The other conclusion from this study is that a higher overall cancer risk with azathioprine treatment cannot be excluded, especially given the apparent effect of duration of therapy. This possible increase in risk has, however, also to be considered against the following: firstly, the dose/response effect was not consistent, maximum daily dose having no apparent effect, and secondly, there was no site specificity, the primary site for the excess cancers being lung, breast, or skin. There were 12 more deaths from all causes recorded in the treated group, but the overall distribution of deaths by major cause was similar in both groups. In conclusion, the increased lymphoproliferative risk from using high doses of azathioprine in patients with RA is about twice that due to RA alone.

The authors wish to thank Dr Leo Kinlen for his helpful advice in preparation of this report. This study was financially supported by the Arthritis and Rheumatism Council and the Wellcome Foundation.

\section{References}

1 Kinlen L J, Sheil A G R, Peto J, Doll R. A collaborative UK-Australian study of cancer in patients treated with immunosuppressive drugs. $\mathrm{Br}$ Med $J$ 1979; ii: 1461-4.

2 Kinlen L J. Incidence of cancer in rheumatoid arthritis and other disorders after immunosuppressive treatment. Am J Med 1985; 78 (suppl 1a): 44-9.

3 Lewis P, Hazleman B L, Hanka R, Roberts S. Causes of death in patients with rheumatoid arthritis with particular reference to azathioprine. Ann Rheum Dis 1980; 39: 457-61.

4 Isomaki H A, Hakulinen T, Joutsenlahti V. Excess risk of lymphomas, leukaemia and myeloma in patients with rheumatoid arthritis. J Chronic Dis 1978; 43: 128-31.

5 Prior P, Symmons D P M, Hawkins C F, Scott D L, Brown R. Cancer morbidity in rheumatoid arthritis. Ann Rheum Dis 1984 43: $128-31$.

6 Monson R R, Hall A P. Mortality among arthritics. J Chront Dis 1976; 29: 459-65.

7 Katusic S, Beard C M, Kurland L T, Weis J W, Bergstrahl E Occurrence of malignant neoplasms in the Rochester, Minnesota, rheumatoid arthritis cohort. Am J Med 1985; 78: (suppl 1a): $50-8$.

8 Prior P. Cancer and rheumatoid arthritis: epidemiologic considerations. Am J Med 1985; 78 (suppl 1a): 15-21.

9 Office of Population Censuses and Surveys. Cancer statistics: Registrations 1974, England and Wales. Series MB1, No 4 London: HMSO, 1980. 